\title{
USEFULNESS OF ADDITIONAL NERVE CONDUCTION TECHNIQUES IN MILD CARPAL TUNNEL SYNDROME
}

\author{
João Aris Kouyoumdjian¹, Maria P. A. Morita², Amalia F. P. Molina ${ }^{3}$
}

\begin{abstract}
This study was done to assess the percentage of abnormality in additional nerve conduction techniques after normal median distal latency (routine) in mild carpal tunnel syndrome (CTS). Bilateral nerve conduction studies were carried out in 116 consecutive symptomatic CTS patients (153 hands). Mild cases were based on normal routine $(<3.7 \mathrm{~ms}$, peak-measured, $14 \mathrm{~cm}$ ) and at least one technique abnormal of the following: sensory median-radial difference (MR); sensory median-ulnar difference (MU4); mixed palm medianulnar difference (MUP); median palm latency (PW); and motor median distal latency (MDL). After normal cutoff values for routine, 3.1 to $3.6 \mathrm{~ms}(<3.7 \mathrm{~ms})$, we found an abnormal MR, ranging from 86.6 to $93.4 \%$, followed by MU4 (40 to $81.7 \%$ ), MUP (20 to 71.2\%), PW (0 to 41.1\%), and MDL (0 to 19.6\%). The most frequent abnormal association were MR plus MU4 in $90.1 \%$, followed by MR plus MUP and MU4 plus MUP. The most frequent abnormal additional nerve conduction technique for mild CTS electrodiagnosis was MR, followed by MU4 and MUP. Percentage of MR abnormality was very high regardless of the median routine latency cut-off ( $<3.1$ to $<3.6 \mathrm{~ms}$ ).
\end{abstract}

KEY WORDS: carpal tunnel syndrome, median nerve, entrapment neuropathy, electrodiagnosis, nerve conduction.

\begin{abstract}
Utilidade de técnicas adicionais de condução nervosa para o dignóstico de síndrome do túnel do carpo leve
RESUMO - Este estudo foi realizado para avaliação da percentagem de anormalidade de técnicas adicionais de condução nervosa no síndrome do túnel do carpo (STC) leve quando o valor de latência distal sensitiva do nervo mediano (rotina) está dentro dos limites normais. Condução nervosa bilateral foi realizada em 116 pacientes consecutivos com STC sintomático (153 mãos). A seleção foi feita baseada na rotina normal $(<3,7$ ms, medida no pico, $14 \mathrm{~cm}$ ) e, pelo menos uma técnica anormal entre as seguintes: diferença sensitiva medianoradial (MR); diferença sensitiva mediano-ulnar (MU4); diferença mediano-ulnar palmar (MUP); latência palmar do mediano (PW); e latência distal motora do mediano (MDL). Os valores normais da rotina foram separados em grupos desde 3,1 até 3,6 ms (< 3,7 ms), obtendo-se valores anormais entre 86,6 e 93,4\% (MR), 40 e $81.7 \%$ (MU4), 20 e $71,2 \%$ (MUP), 0 e 41,1\% (PW) e 0 e 19,6\% (MDL). A associação anormal mais frequente foi MR com MU4 em 90,1\%, seguido de MR com MUP e MU4 com MUP. A técnica adicional isolada anormal mais frequente foi MR seguida de MU4 e MUP. O percentual de anormalidade da técnica MR foi muito elevada, independentemente do valor de corte na condução rotina (3,1 a 3,6 ms).
\end{abstract}

PALAVRAS-CHAVE: síndrome do túnel do carpo, nervo mediano, neuropatia compressiva, eletroneuromiografia, condução nervosa.

Carpal tunnel syndrome (CTS) is the most common entrapment neuropathy in upper limbs. Electrodiagnosis is very sensitive and specific for the diagnosis and several studies have reported sensitivity in the range of 80 to $92 \%^{1}$. Comparison of the sensitivities of the various nerve conduction techniques for CTS diagnosis had demonstrated that sensory conduction is better than motor conduction and the median sensory distal latency in wrist-digit segment
(13 or $14 \mathrm{~cm}$ ) is less sensitive than techniques which evaluate median mixed palm latency $(8 \mathrm{~cm})$ either absolute or comparative to ulnar, or sensory latencies differences from median-ulnar $(14 \mathrm{~cm})$ or median-radial $(10 \mathrm{~cm})$ in the same hand ${ }^{2}$.

The present study was carried out in order to determine the percentage of abnormality of several additional nerve conduction techniques (sensory, mixed and motor) when the routine median antidromic

Electromyography Laboratory, Clinical Neurophysiology, Department of Neurological Sciences, State Medical School, São Jose do Rio Preto SP, Brazil: ${ }^{1}$ Associate-Professor (MD, PhD); ${ }^{2}$ Assistent-Professor (MD, MSc); ${ }^{3}$ Postgraduate Student (MD).

Received 19 April 2002, received in final form 14 June 2002. Accepted 22 June 2002.

Dr. João Aris Kouyoumdjian - Avenida Bady Bassitt 3896 - 15025-000 São José do Rio Preto SP - Brasil. FAX: $5517232-7757$.

E-mail: jaris@terra.com.br 
distal sensorylatency (wrist-indexfinger; $14 \mathrm{~cm}$ ) isfound to be below the upper limit of nomality (ULN).

\section{METHODS}

Patients

From June 1998 to September 2000, 116 consecutive patients with a clinically confirmed diagnosis of CTS were studied, including hand paraesthesia, numbness, and pain mainly at night; isolated pain was not considered. Patients with diabetes mellitus but no electrophysiological evidence of polyneuropathy were included. Cases with only unilateral nerve conduction studies, or previous CTS surgery, asymptomatic subjects, those with clinical or electrophysiological evidence of polyneuropathy, and those with wrist trauma related to CTS side were excluded.

Electrophysiology (nerve conduction studies)

All patients had bilateral nerve conduction studies using Cantata (Dantec, Skovlunde, Denmark) eletromyography machine. Palmar temperatures were maintained above 31 C (digital thermometer, Braile Biomedica, São Jose Rio Preto, SP, Brazil). Electrophysiological techniques are described as follows; all latencies except motor distal latency, were measured to the negative peak; abnormal cut-offs were obtained from the most described data on literature? ${ }^{2}$.

1. Median distal sensory latency (routine). The stimulation delivered on median nerve at wrist activate antidromic sensory action potentials at the second digit; we used a fixed $14 \mathrm{~cm}$ distance from the ring recording electrodes that were placed around the proximal (recording, cathode) and distal (reference, anode) interphalangeal joints. The absolute latency value was defined as abnormal when equal or greater than $3.7 \mathrm{~ms}$.

2. Sensory median-radial difference (MR). Median nerve stimulation was delivered at wrist in order to activate antidromic sensory action potentials at the thumb; we used an approximately $10 \mathrm{~cm}$ distance from the ring recording electrodes around the thumb. Radial nervestimulation was delivered at the lateral edge of the radius in the distal forearm at the same line used for median nerve stimulation; the recording ring electrodes around the thumb were the same. The latency difference was defined as abnormal when equal or greater than $0.50 \mathrm{~ms}$.

3. Sensory median-ulnar difference (MU4). Median nerve stimulation was delivered at wrist in order to activate antidromic sensory action potentials at the fourth digit; we used a fixed $14 \mathrm{~cm}$ distance from the ring recording electrodes that were placed around the proximal (recording, cathode) and distal (reference, anode) interphalangeal joints. Wrist ulnar nerve stimulation was delivered at the same line used for median nerve stimulation. The latency difference was defined as abnormal when equal or greater than $0.40 \mathrm{~ms}$.

4. Mixed median palm latency (PW). Median nerve stimulation was delivered at the palm (mixed nerve) in order to activate orthodromically mainly sensory action potentials at the wrist; we used a fixed $8 \mathrm{~cm}$ distance from the bar recording electrode that were placed at the wrist (cathode distal). The absolute latency value was defined as abnormal when equal or greater than $2.30 \mathrm{~ms}$.

5. Mixed median-ulnar palm difference (MUP). Median nerve stimulation was delivered at the palm (mixed nerve) in order to activate orthodromically mainly sensory action potentials at the wrist; we used a fixed $8 \mathrm{~cm}$ distance from the bar recording electrode that were placed at the wrist (cathode distal). In the same way, ulnar nerve stimulation was done at the palm (ulnar edge) and recording on wrist (ulnar edge). The latency difference was defined as abnormal when equal or greater than $0.40 \mathrm{~ms}$.

6. Median motor distal latency (MDL). Median nerve stimulation was delivered at wrist in order to activate the compound muscular action potential at the thenar eminence; we used a fixed $8 \mathrm{~cm}$ distance from the disc recording electrodes that were placed over the belly of the Abductor Pollicis Brevis muscle (recording, cathode) and just distal to the metacarpophalangeal joint (reference, anode). The absolute latency value was defined as abnormal when equal or greater than $4.40 \mathrm{~ms}$.

Mild CTS cases were defined when routine median sensory distal latency (wrist to index finger; $14 \mathrm{~cm}$ ) was below $3.7 \mathrm{~ms}$ (group 1), below $3.6 \mathrm{~ms}$ (group 2), below $3.5 \mathrm{~ms}$ (group 3), below $3.4 \mathrm{~ms}$ (group 4), below $3.3 \mathrm{~ms}$ (group 5), below $3.2 \mathrm{~ms}$ (group 6), and, below $3.1 \mathrm{~ms}$ (group 7) since the ULN described for the routine median sensory distal latency could vary among different authors. In these groups, at least one additional nerve conduction technique performed, as described above, was found to be abnormal.

All tests were done by the authors using the sameEMG instrument (DANTEC, Cantata); percutaneous stimuli were delivered until supramaximal response obtained; pulse duration were $0.05 / 0.1 \mathrm{~ms}$ for sensory and mixed nerve stimulation and $0.2 / 0.5 \mathrm{~ms}$ for motor nerve stimulation; filters were set at $20 \mathrm{~Hz}$ and $2 \mathrm{kHz}$; the sweep speed was set at $1 \mathrm{~ms}$ per division; bar electrodes or one-centimeter disc recording, either platinum or disposable electrodes, were used for mixed nerve studies and ring electrodes for sensory studies; either disposable or velcro around the forearm were used as ground.

\section{RESULTS}

Mild CTS was identified in 153 hands (70 right and 83 left) from 116 patients. Mean patient age was 46 years (21-71), 94.7\% women. Based on the inclusion criteria - symptomatic hands and at least one abnormal technique among the five tested - we performed the percentage of abnormality of additional techniques when routine median sensory distal latency was less than $3.7 \mathrm{~ms}$ (153 hands), less than $3.6 \mathrm{~ms}$ (131 hands), less than $3.5 \mathrm{~ms}$ (112 hands), less than $3.4 \mathrm{~ms}$ ( 66 hands), less than $3.3 \mathrm{~ms}$ (43 hands), less than $3.2 \mathrm{~ms}$ ( 27 hands), and, less than $3.1 \mathrm{~ms}$ ( 15 hands); the results are showed on Table 1. The percentage of abnormality of MR reaches the 
highest value regardless the seven cut-off routine latency values, ranging from 93.4 to $86.6 \%$. The percentage of abnormality of MU4 reaches the second highest value regardless the seven cut-off routine latency values, ranging from 81.7 to $40 \%$. The percentage of abnormality of MUP reaches the third highest value with a broader variation after the seven cut-off routine latency values ( 71.2 to $20 \%$ ). The percentage of abnormality of PW and MDL reached the smallest value, and, as the cut-off routine latencies drop from less than 3.7 to less than $3.1 \mathrm{~ms}$, they ranged from 41.1 to $0 \%$, and from 19.6 to $0 \%$, respectively. We also evaluated the percentage of abnormality when more than one additional technique were found to be abnormal after normal routine median sensory distal latency (less than $3.7 \mathrm{~ms}$ ) in 131 hands. Abnormality of both MR and MU4 was found in 118/131 hands (90.1\%), followed by MR and MUP in 8/131 hands (6.1\%) and MU4 and MUP in 2/131 hands (1.5\%). Only in 3 hands out of 131 (2.3\%), one of the 2 abnormal techniques were other than MR, MU4 and MUP. Table 2 shows the percentage of abnormality from all 153 hands when at least 1, 2, 3,4 or 5 additional techniques were found abnormal.

\section{DISCUSSION}

Our results clearly showed that the latency differences after sensory median-radial, sensory medianulnar and mixed palm median-ulnar techniques are better than the routine median sensory latency, wrist to index finger, $14 \mathrm{~cm}$, for CTS electrodiagnosis, as stated by AAEM Quality Assurance Committee 2 . These three techniques are above $71.2 \%$ of abnormality when routine sensory conduction is still below the ULN, considered as $3.7 \mathrm{~ms}^{3,4}$. The absolute mixed median palm latency was abnormal in $41.1 \%$ and the median motor distal latency in just $19.6 \%$ pointing out that the most sensitive techniques are the comparative ones. When we considered the ULN for routine sensory as less than $3.6 \mathrm{~ms}$, less than 3.5 $\mathrm{ms}$, less than $3.4 \mathrm{~ms}$, less than $3.3 \mathrm{~ms}$, less than 3.2 ms or even less than $3.1 \mathrm{~ms}$, the percentage of abnormality in comparative technique MR was very high, ranging from 93.4 to $86.6 \%$. MU4 and MUP showed less dramatic positivity ranging from 40 to $81.7 \%$ (MU4) and from 20 to $71.2 \%$ (MUP). This was justified because of in some EMG labs the ULN used for sensory routine could be different. In our previous similar study ${ }^{5}$, we found MR to be abnormal in $97.8 \%$, MUP in $88.4 \%$ and MU4 in $72.6 \%$, but we worked on onset-measured latency and the ULN for routine sensory median distal latency was $3.5 \mathrm{~ms}$ $(40 \mathrm{~m} / \mathrm{s})$. The use of just one abnormal additional technique after normal routine median sensory distal latency should be avoided because of the possible decrease of specificity in CTS electrodiagnosis. Our results showed that when at least 2 additional techniques were abnormal, the most common association was MR plus MU4 (90.1\%) and, in a less extent, MR plus MUP and MU4 plus MUP.

Some considerations should be emphasized about the ideal ULN that we could use to have a correct CTS electrodiagnosis. The cut-off latencies for CTS electrodiagnosis or to define normal values could increase or decrease the sensitivity or specificity leading to false-positive or false-negative electrodiagnosis. The abnormal percentage and the cut-off latencies described in the literature for the techniques have a wide variation and there is no consensus about which one is the best or gold standard and in this study we use a broad range, from a more conservative $3.7 \mathrm{~ms}$ to a less specific $3.1 \mathrm{~ms}$. Because

Table 1. Mild carpal tunnel syndrome and percentage of abnormality of 5 nerve conduction techniques.

\begin{tabular}{|c|c|c|c|c|c|c|c|c|}
\hline \multirow{2}{*}{$\begin{array}{l}\text { Technique } \\
\text { Routine }\end{array}$} & \multicolumn{6}{|c|}{ Abnormality (\%) in each group } & \multicolumn{2}{|c|}{ Abnormal cut-off } \\
\hline & $<3.7 \mathrm{~ms}$ & $<3.6 \mathrm{~ms}$ & $<3.5 \mathrm{~ms}$ & $<3.4 \mathrm{~ms}$ & $<3.3 \mathrm{~ms}$ & $<3.2 \mathrm{~ms}$ & $<3.1 \mathrm{~ms}$ & $>=3.7 \mathrm{~ms}$ \\
\hline Hands & 153 & 131 & 112 & 66 & 43 & 27 & 15 & \\
\hline MR & 93.4 & 93.1 & 92.0 & 89.4 & 86.0 & 85.1 & 86.6 & $>=0.5 \mathrm{~ms}$ \\
\hline MU4 & 81.7 & 80.2 & 77.7 & 68.2 & 65.1 & 51.8 & 40.0 & $>=0.4 \mathrm{~ms}$ \\
\hline MUP & 71.2 & 67.9 & 63.4 & 51.5 & 39.5 & 44.4 & 20.0 & $>=0.4 \mathrm{~ms}$ \\
\hline PW & 41.1 & 32.8 & 25.0 & 10.6 & 0.0 & 0.0 & 0.0 & $>=2.3 \mathrm{~ms}$ \\
\hline MDL & 19.6 & 13.0 & 8.0 & 4.5 & 4.6 & 0.0 & 0.0 & $>=4.4 \mathrm{~ms}$ \\
\hline
\end{tabular}

MR, sensory median-radial difference; MU4, sensory median-ulnar difference; MUP, mixed palm median-ulnar difference; PW, median palm latency; MDL, motor median distal latency. Hands refer to the total (or absolute) number of hands included in each group. 
Table 2. Mild carpal tunnel syndrome and percentage of abnormality for additional techniques.

\begin{tabular}{lcccccc}
\hline Routine** & Hands & $\begin{array}{c}\text { at least } \\
1 \text { abnormal* }\end{array}$ & $\begin{array}{c}\text { at least } \\
\text { 2 abnormals* }\end{array}$ & $\begin{array}{c}\text { at least } \\
\text { 3 abnormals* }\end{array}$ & $\begin{array}{c}\text { at least } \\
4 \text { abnormals* }\end{array}$ & $\begin{array}{c}\text { at least } \\
\text { abnormals* }\end{array}$ \\
\hline$<3.7 \mathrm{~ms}$ & 153 & $100 \%$ & $85.6 \%$ & $67.9 \%$ & $39.9 \%$ & $15.0 \%$ \\
$<3.6 \mathrm{~ms}$ & 131 & $85.6 \%$ & $70.6 \%$ & $54.9 \%$ & $26.8 \%$ & $7.8 \%$ \\
$<3.5 \mathrm{~ms}$ & 112 & $73.2 \%$ & $58.2 \%$ & $43.1 \%$ & $16.3 \%$ & $3.9 \%$ \\
$<3.4 \mathrm{~ms}$ & 66 & $43.1 \%$ & $30.1 \%$ & $19.0 \%$ & $2.6 \%$ & $0.7 \%$ \\
$<3.3 \mathrm{~ms}$ & 43 & $28.1 \%$ & $16.3 \%$ & $9.8 \%$ & $0.7 \%$ & $0.0 \%$ \\
$<3.2 \mathrm{~ms}$ & 27 & $17.6 \%$ & $7.2 \%$ & $3.9 \%$ & $0.0 \%$ & $0.0 \%$ \\
$<3.1 \mathrm{~ms}$ & 15 & $9.8 \%$ & $2.6 \%$ & $2.0 \%$ & $0.0 \%$ & $0.0 \%$ \\
\hline
\end{tabular}

of median and radial nerve stimulation was delivered at the same line (wrist for median and lateral edge of the radius for radial nerve) instead of $1 \mathrm{~cm}$ above on radial nerve stimulation, we considered abnormal latency difference as $>=0.5 \mathrm{~ms}$ and not as $0.4 \mathrm{~ms}$, as described in several papers².

Reports of abnormal percentage for MR are described as $44 \%^{6,7}, 58 \%^{7}, 59.6 \%^{8}, 87.2 \%^{9}, 89 \%^{10}$, $90 \%{ }^{11}$, and $100 \%{ }^{12}$. Reports of abnormal percentage for MU4 are described as $42 \%^{11}, 44 \%^{6}, 78 \%^{13}, 87 \%^{14}$, $88.6 \%^{9}, 93 \%^{15}, 99.2 \%^{10}$, and $100 \%^{16,17}$. Reports of abnormal percentage for MUP are described as $30 \%$, $57 \%^{18}, 60 \%{ }^{19}$ and $61 \%^{11}$. The possible cause of variability in the results could be mainly due to the cutoff latency value for routine median sensory nerve conduction that, in our opinion, should always be below ULN. If the purpose of the study is to find out which technique is the most useful, we should establish the ULN of each one and after that include in the results at least one abnormal value. It could be argued that some patients were false positive because the ULN used in this study could be found in some normal individuals according to population selection ${ }^{1}$. In addition, it is important to include just hands in which routine median sensory distal latency is below the ULN in order to select only mild cases and prevents high percentage of abnormality. Probably all cases could show abnormality in comparative techniques (more sensitivetechniques) if the routine median distal sensory latency is equal or higher than $3.7 \mathrm{~ms}$, peak-measured.

As stated before, a very interesting and puzzling finding of our results was the fact that even after the routine median sensory distal latency decreased from 3.7 to $3.1 \mathrm{~ms}$, the percentage MR abnormality went down just a little (93.4 to 86.6\%) when com- pared to MU4 (81.7 to $40 \%$ ) or MUP (71.2 to $20 \%$ ). Why the median-radial latency difference maintains a high percentage of abnormality whereas the other techniques diminished more proportionally in accordance to the reduction of routine median sensory distal latency? Should we consider the ULN more than 0.5 ms for MR or it is just a matter of a greater susceptibility of the median fascicle for thumb?

It should be emphasized that our results do not represent the real sensitivity of the electrodiagnosis tests in CTS because we always include hands with at least one abnormal technique; the purpose was to compare the most sensitive among them. Also, we believed that when only one abnormal comparative technique is found together with normal routine median sensory distal latency it should be considered possible or incipient CTS; nerve conduction studies follow-up should be further required. Redmond and Rivner $^{20}$ emphasized the increment of false-positive CTS electrodiagnosis after the use of additional techniques. More than one abnormal additional technique could be found to keep a high specificity ${ }^{1}$. If more than one comparative technique is found above ULN even with normal routine median sensory distal latency the CTS electrodiagnosis is more reliable.

\section{REFERENCES}

1. Andary MT, Werner RA. Electrodiagnosis in clinical decision making: carpal tunnel syndrome. 1997 AAEM CourseB: Using electrodiagnosis in clinical decision making. AAEM 20th Annual Continuing Education Courses 1997, San Diego, USA.

2. Jablecki CK, Andary MT, So YT, Wilkins DE, Willians FH. Literature review of the usefulness of nerve conduction studies and electromyography for the evaluation of patients with carpal tunnel syndrome. Muscle Nerve 1993;16:1392-1414.

3. Johnson EW, Melvin JL. Sensory conduction studies of median and ulnar nerves. Arch Phys Med Rehabil 1967;48:25-30.

4. Di Benedetto M, Mitz M, Klingbeil GE, Davidoff D. New criteria for sensory nerveconduction especially useful in diagnosing carpal tunnel syndrome. Arch Phys Med Rehabil 1986;67:586-589. 
5. Kouyoumdjian JA, Morita MPA. Comparison of nerve conduction techniques in 95 mild carpal tunnel hands. Arq Neuropsquiatr 1999;57:195-197.

6. Jackson D, Clifford JC. Electrodiagnosis of mild carpal tunnel syndrome. Arch Phys Med Rehabil 1989;70:199-204.

7. White JC, Hansen SR, Johnson RK. A comparison of EMG procedures in the carpal tunnel syndrome with clinical-EMG correlations. Muscle Nerve 1988;11:1177-1182.

8. Carrol G. Comparison of the median and radial sensory latencies in the electrophysiological diagnosis of carpal tunnel syndrome. Electroencephalogr Clin Neurophysiol 1987;68:101-106.

9. PeaseWS, Cannell CD, Johnson EW. Median to radial latency difference test in mild carpal tunnel syndrome. Muscle Nerve 1989;12:905-909.

10. Cioni R, Passero S, Paradiso C, Giannini F, Battistini N, Rushworth G. Diagnostic specificity of sensory and motor nerve conduction variables in early detection of carpal tunnel syndrome. J Neurol 1989;236:208-213.

11. Andary MT, Fankhauser MJ, Ritson JL, et al. Comparison of sensory mid-palm studies to other techniques in carpal tunnel syndrome. Electromyogr Clin Neurophysiol 1996;36:279-285.

12. Johnson EW, Sipski M, Lammertse T. Median and radial sensory latencies to digit I: normal values and usefulness in carpal tunnel syndrome. Arch Phys Med Rehabil 1987;68:140-141.
13. Uncini A, Lange DJ, Solomon M, Soliven B, Meer J, Lovelace RE. Ring finger testing in carpal tunnel syndrome: a comparative study of diagnostic utility. Muscle Nerve 1989;12:735-741.

14. Lauritzen M, Liguori R, Trojaborg W. Orthodromic sensory conduction along the ring finger in normal subjects and in patients with a carpal tunnel syndrome. Electroencephalogr Clin Neurophysiol 1991;81:18-23.

15. Monga TN, Laidlow DM. Carpal tunnel syndrome measurement of sensory potentials using ring and index fingers. Am J Phys Med 1982;61:123-129.

16. Johnson EW, Kukla RD, Wongsam PE, Piedmont A. Sensory latencies to thering finger: normal values and relation to carpal tunnel syndrome. Arch Phys Med Rehabil 1981;62:206-208.

17. Charles N, Vial C, Chauplannaz G, Bady B. Clinical validation of antidromic stimulation of thering finger in early electrodiagnosis of mild carpal tunne syndrome. Electroencephalogr Clin Neurophysiol 1990;76:142-147.

18. Kim LYS. Palmar digital stimulation to diagnose carpal tunnel syndrome. Orthop Rev 1983;(6):59-63.

19. Mills KR. Orthodromic sensory action potentials from palmar stimulation in the diagnosis of carpal tunnel syndrome. J Neurol Neurosurg Psychiatry 1985;48:250-255.

20. Redmond MD, Rivner MH. False positive electrodiagnostic tests in carpal tunnel syndrome. Muscle Nerve 1988;11:511-517. 